\title{
Communication Approaches of Hearing-Impaired Students in an English Language Learning Classroom: The Case of a Public Elementary School
}

\author{
Prences Mae M. Langga ${ }^{1} 8$ (D) $\triangle$, Kithamae N. Sabandal ${ }^{2}$ (D), Asst. Prof. Roseniya T. Datu-Ulama ${ }^{3}$ (D), \\ Assoc. Prof. Dr. Wardah D. Guimba 4 (D) Adelyn N. Sialana-Nalla 8 (D) and Jerryk C. Alico 8 (D) \\ ${ }^{1}$ Philippine Engineering and Agro-Industrial College, Inc., Marawi City, Philippines \\ 2Surigao Education Center High School, Surigao City, Philippines \\ ${ }^{345}$ College of Education, Mindanao State University, Marawi City, Philippines \\ ${ }^{6}$ English Department, College of Social Sciences and Humanities, Mindanao State University, Marawi City, Philippines \\ $\triangle$ Corresponding Author: Jerryk C. Alico, E-mail: jerryk.alico@msumain.edu.ph
}

\section{ARTICLE INFORMATION}

Received: March 08, 2021

Accepted: April 22, 2021

Volume: 3

Issue: 4

DOI: 10.32996/ijels.2021.3.4.8

\section{KEYWORDS}

Communication Approaches, Hearing-Impaired, Sign Language, Finger Spelling, English Learning Difficulties

\section{ABSTRACT}

English as a second language (ESL) learning among hearing-impaired individuals is a unique area that has not been widely investigated in Southern Philippines, where Special Education (SPED) Program is still emerging. To fill in this gap, this qualitative study dealt with the communication approaches of hearing-impaired students to learn English. The participants were six students and one SPED teacher. Semistructured interviews and non-participant observation were employed to determine the participants' communication approaches and challenges in expressing themselves using the target language. Findings disclosed that all participants used sign language based on Manually Coded System and fingerspelling while only the teacher communicated with the aid of speech and visuals. Students' and teacher's challenges in English learning and teaching, respectively, were students' problematic retention, apprehensive behavior during class evaluations, and slow comprehension. This paper has its limitation for other variables that could make the study more relevant were not focused such as the hearing-impaired students' medical backgrounds, writing skills, and communicative resources available at home. Hence, it is imperative that further studies be done to shed better light on hearing-impaired students' English language learning.

\section{Introduction}

One of the important facets of human life is communication-the process of sharing ideas verbally and non-verbally. It is a necessity to establish a harmonious relationship with other people to survive. The ability to communicate is innate; however, there are various skills that humans must possess to convey ideas and feelings and, of course, to avoid misunderstanding. One of these important skills is listening, which is needed in learning a language. As such, hearing-impaired individuals obviously lack listening, which leads to problems as far as social interaction is concerned.

According to Simon and Fennig (2017) in their book Ethnologue: Languages of the World, the Philippines' deaf population is approximately 2,914,600. With regard to this, 25 provinces in Mindanao have recognized Special Education Schools. In the province of Surigao del Norte, four elementary schools offer Special Education Program, namely: Dapa Central Elementary School, Socorro Central Elementary School, Sison Central Elementary School, and Mariano Espina Memorial Central Elementary School (National Council on Disability Affairs, 2012). These Special Education schools cater to individuals with various disabilities, including hearing impairment.

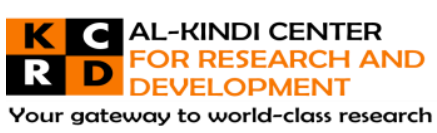

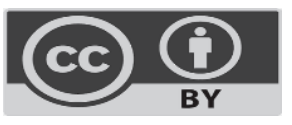

Published by Al-Kindi Center for Research and Development. Copyright (c) the author(s). This open access article is distributed under a Creative Commons Attribution (CC-BY) 4.0 license 
Hearing impairment is the absence or decreased ability of auditory perception that can impair an individual in processing linguistic information through hearing. A hearing loss occurs when any problem with one or more parts of the ear or ears decreases the ability to receive auditory information (Myers, 2000). Moravkova (2011) characterizes types of deafness from several points of view, such as the time when the deafness occurred (pre-lingual and post-lingual deafness), the part of the body that affects the ability to hear (conductive and perceptive hearing loss), and the degree of deafness (according to the sound volume that is measured in the decibels which could be mild, moderate, moderately severe, severe or profound). Moravkova argues that the type of deafness influences the choice of communication approaches or options that facilitate language development and allows one to readily engage in communication interchanges.

Gravel and O'Gara (2003) point out factors impacting the selection of a communication approach for children who are hard of hearing. These are the language used at home, family involvement, age of identification and intervention, literacy, community resources, hearing status, hearing aids and cochlear implants, speech intelligibility, presence of additional disabilities, and availability of later educational options. However, Gravel and O'Gara conclude that no one option is best for every child and that selecting one communication option does not preclude a change of that approach at one or more points in childhood.

Early identification of hearing loss is a must, according to Bustos (2009), because it will enable parents to choose a communication mode that best suits their hearing-impaired children. Wise (2006), as cited by Bustos (2009), reported that the success of deaf emergent readers depends on their families' commitment to a communication mode. Bustos also recommended that the visual inclination of deaf children be considered when choosing the communication mode. To support this, Martin (2009) maintains that the upshot of the hearing-impaired individuals' language learning process, be it first, second, or even third language learning, is potentially determined by their primary language environment where parents play an essential role as one of the decisive factors.

In addition, hearing loss significantly influences the language and speech development of students who are deaf and hard-ofhearing, which then negatively affects their academic achievement, social and emotional interaction, and cognitive milestones (Moores, 2001 cited by El-Zraigat and Smadi, 2012). According to El-Zraigat (2007), deaf and hard-of-hearing students have poor expressive writing skills and lack adequate reading skills in general (Mayberry, 2001).

In view of the foregoing premises, the researchers took an interest in extending the discussions on the communication experiences of hearing-impaired children, particularly in the context of an inclusive public elementary school. This paper specifically aims to determine the different communication approaches and the challenges of hearing-impaired students of Mariano Espina Memorial Central Elementary School (MEMCES), Surigao City, Surigao del Norte, in learning English language. The communication approaches and challenges of the SPED teacher in teaching English language are also determined to explore further the case of said hearing-impaired students.

\section{Literature Review}

\subsection{Deaf and Sign Language}

Sign language is based on the visual-motion code with a codified system of characters given by basic positions, hand movements with facial expressions, postures and movements in addition to all hands to apply various changes, especially finger positions (Horňakova \& Hudakova, 2013). Sign languages are not derived from spoken languages; they have their own independent vocabularies and their own grammatical structures. Although there exist contrived sign systems that are based on spoken languages (such as Signed English, Signed Hebrew, etc.), such systems are not natural languages (Sandler \& Lillo-Martin, 2001).

According to Hurlbut (2008), deaf children who have deaf and signing parents (native signers) naturally acquire sign language very much in the same way as hearing children acquire spoken languages. Deaf children exposed to sign language from birth do not lag behind in language acquisition at all. There are pieces of evidence that deaf children acquire sign language faster than hearing children acquire spoken language.

On the other hand, deaf children with hearing parents (non-native signers) begin their language acquisition after the age of six (the critical period or the limited time span wherein children's brains are only capable of fully acquiring a language is over) and their sign language show permanent traces of delayed acquisition. Ninety per cent of deaf children are born to hearing parents, and most parents choose not to learn sign language but a sign system that consists of signs but follows the grammatical rules of their first language (Julsrud, 2011). 
Mayberry (2002) revealed that children with hearing parents develop home signing systems (self-developed gesture system) merely from the gestures they see around them. There were three gesture systems presented, namely pointing gestures, iconic gestures, and conversational gestures. First, the pointing gestures which are used as nouns and pronouns, e.g.to refer to both present and non-present objects, places, and people; and their headshakes have the properties of the negations "not" and "can't". The point itself does not refer to what the object is, only where it is. Second, the iconic gestures (called "characterizing" gestures by Goldin-Meadow, 1977 as cited by Mayberry, 2002) is used to display what has happened in a given situation or what is actually going on at the present moment in the conversation. Lastly, the conversational gestures refer to modulating gestures representing a group of gestures borrowed from spoken conversational gestures. The three most common conversational gestures are nods, side-to-side headshakes, and one- or two-handed flips.

\subsection{Deaf and Communication}

Acquiring and developing good communication skills is crucial for hearing-impaired children and their families. The acquisition of good communication skills will help the child in all areas of their development, including intellectual, emotional, personal and social skills. If the hearing-impaired child uses a hearing aid or cochlear implant, it is extremely important that parents are persistent with their child regarding wearing their hearing aid or cochlear implant. Equally, if the child uses sign language, it is important that as many people as possible in the child's social circle are encouraged to learn to communicate fluently in sign language.

A communication option, mode, modality, approach or method refers to the ways a child with hearing loss naturally adopts when interacting with other people. It is the means by which the child and family receive and express language (Carney \& Moeller, 1998 as cited by Gravel \& O'Gara, 2003).

\subsubsection{Auditory- Verbal (AV) Approach}

The Auditory-Verbal approach aims to acquire language through aided residual hearing and completely integrate the hard of hearing or deaf child into the community of individuals who use spoken language. Consistent (every waking hour) use of amplification or cochlear implant technology is considered requisite for achieving the goals set forth in the approach (Goldberg, 1997). Audition is stressed so significantly that during language learning activities, the child is not permitted to view the lips or facial expressions of the speaker. Because the goal is complete integration in the mainstream, the child and family are not exposed to Deaf culture or sign language.

\subsubsection{Cued Speech Approach}

Cued Speech (Cornett, 1967) comprises eight different handshapes and four different hand locations around the speaker's face. Each of the eight handshapes represents a group of consonants. Consonants within a handshape group are distinguished through lip-reading. Vowels are cued by moving the hand to one of four locations around the lower face and neck (at the lips, side of the lips, chin, and throat), with lip shape distinguishing the vowels within a vowel group. The receiver of the cued speech observes the speaker's hand pattern, hand location, and lip position in order to distinguish among individual speech sounds; none is visually ambiguous.

\subsubsection{Manually Coded English}

Manually Coded English (MCE) is a visual representation of the spoken English language (Gustason, 1997). Signs and fingerspelling are used to represent spoken English. Syntax follows the rules of spoken English; lexical items without specific signs are fingerspelled. Grammatical morphemes are conveyed by gestures or fingerspelling. Amplification is not necessary for an individual who uses a form of MCE.

\subsubsection{American Sign Language (ASL)}

American Sign Language (ASL) is a naturally evolved visual language used by the Deaf community in the U.S. Many members of the Deaf community, however, consider themselves bilingual: use both ASL and some form of spoken language (Manually Coded English) when communicating with the Deaf and hearing communities, respectively (Baker \& Baker, 1997).

\subsubsection{Bilingual- Bicultural Approach}

Bilingual Bicultural approach is a means of promoting literacy development in Deaf learners through respecting and using "both the Sign Language of the Deaf community and the spoken/written language of the hearing community" (Gregory, 1998). In this approach, the primary medium of instruction is sign language and learners are introduced through sign language to literacy in the written (second) language. 


\subsubsection{Oral- Aural Approach}

The Oral-Aural approach to the education of deaf learners emphasizes auditory skills through speech and language therapy that focuses on residual hearing using assistive devices and aims to teach deaf children to speak so that they are able to communicate with the hearing world. These may include hearing aids, FM systems (Frequency Modulation) and Cochlea Implants. This approach strives to make the most of a child's listening abilities as well as encourages lip-reading skills. Oralists believe that deaf children will acquire spoken languages through seeing and 'hearing' them, and that this language acquisition will lead to more complete integration with the hearing world (Johnson, Liddell \& Erting, 1989).

\subsubsection{Total Communication (TC)}

Total communication is the most widely used communication method in educational settings for the deaf. A variety of methods such as finger spelling (the Sign Language alphabet), mime, writing, pictures, lip-reading, gestures and oral speech may be used. The use of residual hearing via amplification such as hearing aids, cochlea implants and FM systems (Frequency Modulation) is also strongly encouraged. Another commonly used term for total communication is simultaneous communication, known as simcom (Berke, 2011).

\subsection{Deaf and English Language Learning}

In order to integrate fully into a predominantly hearing world, the deaf child is faced with a particular challenge of adapting to an education system that provides for bilingual education. In such a situation, sign language should feature as first language or mother tongue and language of instruction under ideal circumstances, but for purposes of reading and writing, the deaf child should also be exposed to a second spoken language (Akach, 2010).

Berent (2001) cited that a wide knowledge of English both in English and non-English speaking countries is a critical factor in the success and the attainment of gainful employment of both deaf and hearing students. A good, functional knowledge of English is essential for accessing the wealth of English-language information disseminated via the World Wide Web, for example, and through other educational and technological sources. With respect to teaching English to deaf students, factors related to firstlanguage acquisition, second-language acquisition, and the special situation of deaf students learning the grammar of a spoken language are all involved. These interacting factors will present unique challenges to deaf students who are studying English in a non-English-speaking environment.

In America, the acquisition of English language and literacy skills probably represents the most formidable challenge confronting educators of deaf students, having implications for both assessment and instruction. To address the instructional needs of students with limited English proficiency, appropriate assessment tools are necessary. For example, postsecondary educational programs serving deaf students need valid and reliable assessments in order to make admissions and placement decisions. However, conventional admissions and placement tests are not appropriate for applicants having limited English proficiency, including the majority of deaf applicants. Accordingly, assessments designed to measure the English skills of foreign students, such as the Test of English as a Foreign Language (TOEFL) and the Michigan Test of English Language Proficiency, can be considered alternatives to conventional admissions and placement tests for deaf students (Bochner \& Walter, 2005).

Kretschmer (1997) argues that there is a need to refocus English instruction for children with hearing loss to language learning, especially discourse features, rather than to language conventions. Language intervention, through the collaborative efforts of speech-language pathologists and teachers, should promote communication interactions that emphasize English discourse that facilitates interpersonal and school language learning. Discourse processes could be in narration, description, explanation, persuasion or instruction giving.

\subsection{Previous Studies}

Two studies that discuss how hearing impairment and chosen communication approaches affect literacy performance and two more that aimed to appraise challenges hearing-impaired students encounter in learning a language are the highlights of this section.

\subsubsection{Communication Approaches to Deaf Literacy Performance}

Deafness has a profound effect on literacy performance (Bustos, 2009). The study of Bustos (2009), an exploratory, descriptive study of the emergent literacy behaviors of Filipino deaf children, investigated the unique literacy behaviors of oral and signing deaf children and reports these behaviors in three categories: early reading, early writing, and book orientation behaviors. The study used moderate participant observation as the main data collection technique. Purposive sampling was used to select two groups of deaf children: the first sample was from an oral school (composed of five girls and three boys), while the second sample was from a school that used manual communication (composed of six boys and three girls). 
Bustos (2009) reported that while hearing children are dependent on oral-aural channels, deaf children are dependent on the visual-gestural channel. Their literacy behaviors are grounded on this visual orientation. The attention and meaning deaf children attach to books center on pictures and how they form a story when presented in a sequence. Even the children's retelling of stories is picture-governed. Deaf children's strategies for reading and writing also use visual orientation. Signing children use sign to-print strategies, which involve finding correspondences between the hand-shape of a word and its written form. Some oral children show a semblance of an awareness of grapheme-phoneme relationships by babbling when they see the printed text.

The study of Bustos (2009) was supported by Bucur's (2013) study on the role of visual teaching aids in the introduction of literary text to 10 hearing-impaired children of $4^{\text {th }}$ grade, respectively $5^{\text {th }}$ grade (ages between 10 to 12 ) in the context of total communication concluded two things. First, it was found that the use of total communication offers access to the significance of words, statements, texts and conversations. Through it, the hearing-impaired child truly understands the message conveyed and does not answer mechanically but in full knowledge of it. Second, by images, the hearing-impaired child has access to the concrete perception of objects or phenomena they speak. Images offer the connection between the word and its significance and facilitate the formation of mental representations of concepts. This study used 11 fragments of various literary texts. The period of work for a literary text was two weeks, respectively 12 classes of Romanian.

\subsubsection{English Languages Learning Challenges}

The thesis of Martin (2009) entitled "Language Learning and Deafness" aims to shed light on the specific factors defining the way of the deaf individuals in learning a foreign language (English). The existent findings regarding first and second language acquisition of the deaf in the USA and the Czech Republic are examined, as well as the product of the methods used to facilitate the process of acquisition. Martin used a standardized open- ended type of questions in interviewing four deaf individuals (two were deaf educators and two were college students). Martin suggested that the greatest challenge confronting all deaf individuals learning an auditory-oral language, either Czech or English, is the fact that the deaf do not receive direct input in a language the written system of which they are supposed to master. In other words, their intramental activities are carried out in sign language, whereas the written code is based on another language.

It is essential for deaf and hard-of-hearing students to have continuous interaction to improve their communication skills, participation in academic learning, and socialization in a hearing society. This is where the notion of inclusion of the deaf and hard of hearing students with hearing teachers and peers in a regular classroom comes from. This will provide a better chance of daily interaction. However, the qualitative case study of Asif (2004) tells that various difficulties are encountered during interaction. The respondents are a deaf student, a hearing student, and their class teacher in an inclusive school located in Tilburg, the Netherlands. Data were collected through semi-structured interviews and non-participant observations of the class in which the deaf student is studying, were done during five different subjects. The results showed that the deaf student's receptive and expressive language difficulties, noisy classroom environment, limited use of the hearing devices, speaking fast by the teachers, and hearing peers occasionally, impacts of multilingualism on deaf's speech language development, low selfesteem and confidence, limited participation of the deaf student in lessons and discussions were the difficulties for the deaf student and his interaction partners when interacting in the classroom.

\section{Methodology}

\subsection{Research Design}

This study employed mixed methods to examine the challenges and approaches used by the hearing-impaired students and their SPED teacher in learning and teaching English language respectively. This strategy aims to investigate the quality of relationships, activities, or situations and to understand the experiences of the participants as nearly as they feel (Fraenkel and Wallen, 2006). The researchers performed the data collection by means of questionnaire, interview, and observation.

\subsection{Locale and Participants of the Study}

This study was conducted at Mariano Espina Memorial Central Elementary School (MEMCES; School ID. 132254), an inclusive public school in District I, Surigao City, Surigao del Norte, Philippines. The participants of the study were six (6) hearing-impaired students and the adviser of MEMCES SPED Hearing-Impaired Section. The hearing-impaired students varied in grade level and age: two were in Grade 4 ( 25 and 14 years old), two were in Grade 5 (both were 14 years old), and two were in Grade 6 (16 and 45 years old). This signifies the diversity of the students' knowledge level of intelligible communication and English language using different communication approaches. Based on the students' age, their grade levels, especially those with ages 25 and 45 , are not proportional to where hearing students usually belong. Furthermore, their promotion to the next grade level is a manifestation that they have already mastered the skills imperative on a particular level. It is important to note that they were 
taught the same lessons from Grades 4 to 6 and it was upon the evaluation of the teacher whether or not they can proceed to the next grade.

The SPED teacher has been in service for 19 years and has been teaching the hearing-impaired students' multi-grade classroom. She teaches them the same lessons based on the K-12 curriculum, but the lessons are simplified to match the students' level. In the end, she decides who will pass and who will be retained according to the students' mastery of the subject matter.

\subsection{Instrumentation}

The instrument used in this study has two parts. The first part was adapted from the study of Martin (2009) entitled Language Learning and Deafness. Seven (7) out seventeen (17) questions were retained because of their usability and relevance in this study. It was used to identify the hearing-impaired-students' personal profile in terms of age, grade level, number of repetition(s) in a particular grade level, mother tongue and hearing condition of the parents/guardians. This questionnaire further identifies the students' communication approach(es) in English language learning.

The second part was used to glean data about the teacher's total number of years in service, communication approaches used in teaching, and challenges in English language teaching. This questionnaire was adapted from the study of Raga (2014), which contains six (6) questions out of the twelve (12) original ones in Raga's study.

\subsection{Data Gathering Procedure}

The data collection consumed ten days overall where the last two days was spent for the interview. All the interviews were conducted face-to-face with the interviewees using the adapted interview questionnaires. The interviews with the hearingimpaired students were done simultaneously together with the teacher, and after which, she was interviewed. Moreover, the researchers recorded videos during class discussions and interviews as well with the consent of the teacher.

The semi-structured format was employed during the interview. According to Robson (2002), questions in this interview can be predetermined and changed, omitted, modified, or added according to appropriateness or needs. On the other hand, the nonparticipant observation approach, where researchers are not directly involved in the situation they are observing (Fraenkel and Wallen, 2006), was applied in observing the hearing-impaired students.

The researchers sought help from experts, specifically from the teacher, in gathering the data. The final transcript was composed after series of scrutiny done by the researchers with the help of experts in sign language, and the said transcript was presented to the respondents for approval.

\section{Results and Discussion}

\subsection{Communication Approaches to English Language}

Results and analysis of participants' answers are presented in the succeeding tables. The teacher did the interviews with students while the researchers conducted non-participant observation. The communication approaches used by the teacher and the students in asking the questions and responding to the interviewer, respectively, are shown below.

Table 1: Students' Answers to Questions 1 \& 2, Teacher's and Students' Communication Approach/es

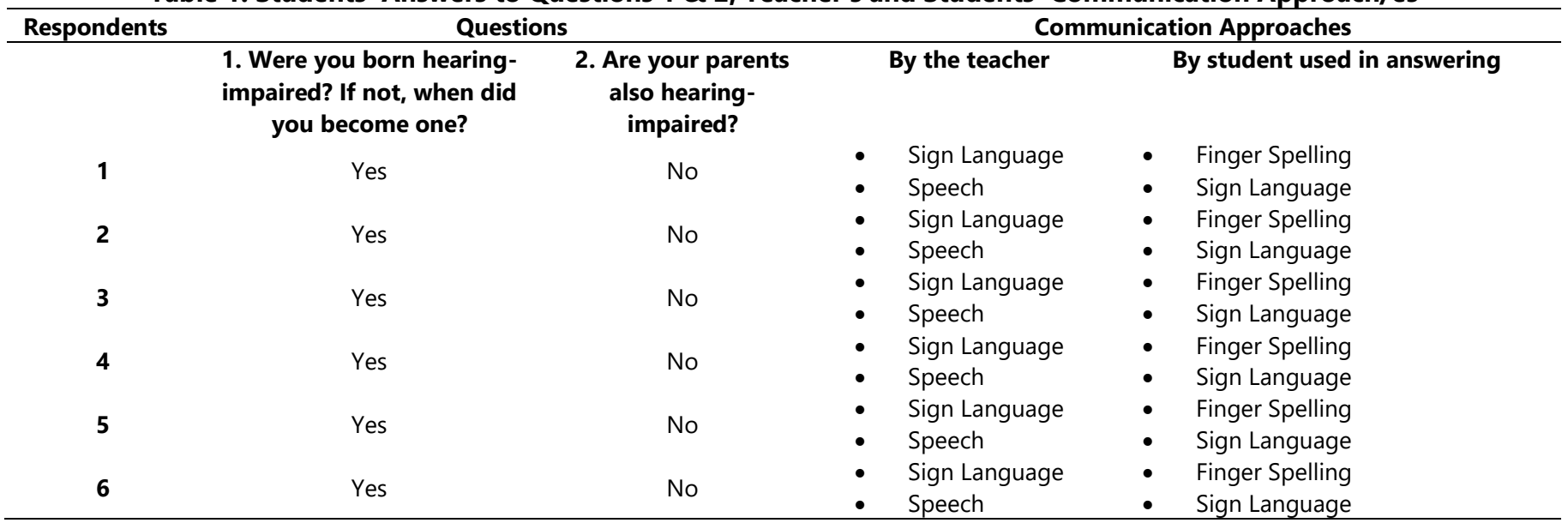


Table 1 reveals the answers of the students to questions $1 \& 2$ of the questionnaire. The teacher was the one who cast the questions using sign language and speech. Data show that all student-participants were born hearing-impaired with hearing parents. This implies that the students did not have common contact with their parents or guardians during childhood and interaction opportunities were less. This suggests that they had difficulty acquiring their first language because aside from they cannot hear, they did not have a model whom they can imitate and there was no one who would properly teach them how to communicate (Hurlbut, 2008; Julsrud, 2011). Further, before answering the two questions, the teacher asked first their name and age. It was observed that all of the participants used sign language and finger spelling in responding.

Table 2: Students' Answer to Questions 3 \& 4, Teacher's and Students' Communication Approach/es

\begin{tabular}{|c|c|c|c|c|}
\hline \multirow[t]{2}{*}{ Respondents } & \multicolumn{2}{|r|}{ Questions } & \multicolumn{2}{|c|}{ Communication Approaches } \\
\hline & $\begin{array}{l}\text { 3. What do you } \\
\text { consider your first } \\
\text { language? }\end{array}$ & $\begin{array}{l}\text { 4. How did you communicate with } \\
\text { your parents in your early childhood? }\end{array}$ & Teacher & Student \\
\hline 2 & Home Sign System & None & Sign Language, Speech & Sign Language \\
\hline 3 & Home Sign System & None & Sign Language, Speech & Sign Language \\
\hline 6 & Home Sign System & Home Sign System & Sign Language, Speech & Sign Language \\
\hline
\end{tabular}

Table 2 presents students' answer to questions $3 \& 4$, and the teacher's and the students' communication approach/es. As depicted, all student-participants attested that their mother tongue is the home sign system. Home sign systems are selfdeveloped gesture system of deaf individuals with hearing parents or guardians. It does not possess proper structure or pattern and grammar but is only formed by pure gesticulations (Goldin-Meadow, 2003). This data, which agree with the research of Goldin-Meadow (2003), entail that even if they have hearing parents whose way of communicating is dominated by speech, hearing-impaired students can still acquire a medium that would aid their interaction with other people.

Four of the student-participants used home sign system in communicating with parents during their childhood. This means that even though their language development was late, they still acquired a method or mode to communicate. On the other hand, two answered none as their mode or approach of communication their childhood. This contradicts their answer to question 3 in which they answered the home sign system as the first language. The researchers suspect that there could be several factors affecting this contradiction.

In employing the questions to the students, the teacher used speech and sign language all throughout while all or $100 \%$ of the students used sign language in responding to the question.

Table 3: Students' Answer to Question 5, Teacher's and Students' Communication Approach/es

\begin{tabular}{cccc}
\hline Respondents & Question & \multicolumn{2}{c}{ Communication Approaches } \\
\cline { 2 - 4 } & $\begin{array}{c}\text { 5. When did you first } \\
\text { come into contact with } \\
\text { English? }\end{array}$ & Teacher & Students \\
$\mathbf{1}$ & School & Sign Language, Speaking & Sign Language \\
$\mathbf{2}$ & School & Sign Language, Speaking & Sign Language \\
$\mathbf{3}$ & School & Sign Language, Speaking & Sign Language \\
$\mathbf{4}$ & School & Sign Language, Speaking & Sign Language \\
$\mathbf{5}$ & School & Sign Language, Speaking & Sign Language \\
$\mathbf{6}$ & School & Sign Language, Speaking, Finger Spell & Sign Language \\
\hline
\end{tabular}

Table 3 shows the students' answers to question 5 and the teacher's and the students' communication approach/es. As can be noticed, all of the student-participants confirmed that their first contact with English language was in school. This implies that it is only in school they learned the proper and structured sign language. This explains their slow-paced learning of two different areas-the formal sign language and the English language itself. The participants' age and their guardians' hearing condition make a relevant input signifying that no sufficient resources, which these participants could learn from at home, were present.

With regard to this, the teacher chose sign language and speaking to address all the students and finger spelling, as additional, to one of the respondents. It was observed that all respondents had sign language as a communication approach. 
Table 4: Students' Answer to Question 6, Teacher's and Students' Communication Approach/es

\begin{tabular}{cllc}
\hline Respondents & \multicolumn{1}{c}{ Questions } & \multicolumn{1}{c}{ Communication Approaches } \\
\cline { 2 - 4 } & 6. How do you master English & Teacher & Students \\
$\mathbf{1}$ & Study and memorize & Sign Language, Speaking & Sign Language \\
$\mathbf{2}$ & Study & Sign Language, Speaking & Sign Language \\
$\mathbf{3}$ & Study and practice & Sign Language, Speaking & Sign Language \\
$\mathbf{4}$ & Study and memorize & Sign Language, Speaking & Sign Language \\
$\mathbf{5}$ & Study and practice & Sign Language, Speaking & Sign Language \\
$\mathbf{6}$ & Study and practice & Sign Language, Speaking & Sign Language \\
\hline
\end{tabular}

Table 5 shows students' answers to question 6 and the teacher's and the students' communication approach/es. As noted, two student-participants answered through studying, and memorizing, three said through studying and practicing and only one expressed through studying. All had studying as a common denominator. This connotes that, albeit the hearing impairment, they have the ability to learn additional language and acquire the learning macro skills just like hearing individuals do (Julsrud, 2011). These responses agree with the findings of Moravkova (2011) regarding deaf individuals' knowledge about the importance and motivation in learning English language.

On the other hand, the teacher used sign language and speaking to address all the students and finger spelling, as additional, to one of the respondents. It was confirmed that all of the respondents used sign language as a communication approach in responding to the question.

Table 6: Students' Answer to Question 7, Teacher's and Students' Communication Approach/es

\begin{tabular}{|c|c|c|c|}
\hline \multirow[t]{2}{*}{ Respondents } & Question & \multicolumn{2}{|c|}{ Communication Approaches } \\
\hline & $\begin{array}{l}\text { 7. What challenges can you } \\
\text { identify in learning English } \\
\text { language? }\end{array}$ & Teacher & Students \\
\hline 1 & $\begin{array}{l}\text { Many words are difficult to } \\
\text { understand and to express }\end{array}$ & Sign Language, speech & Sign Language \\
\hline 2 & Difficult to understand. & Sign Language, speech & Sign Language \\
\hline 3 & Difficult to understand. & Sign Language, speech & Sign Language \\
\hline 4 & Difficult to understand. & Sign Language, speech & Sign Language \\
\hline 5 & $\begin{array}{l}\text { Difficult to understand, lots of words } \\
\text { are difficult to memorize }\end{array}$ & Sign Language, speech & Sign Language \\
\hline 6 & Difficult to understand. & Sign Language, speech & Sign Language \\
\hline
\end{tabular}

Table 6 presents students' answers to question 6 and the teacher's and the students' communication approach/es. As portrayed, all of the student-participants stated difficult to understand, and only one added that sometimes, words are difficult to express and there are lots of words to memorize. Learning an additional language is no easy but the presence of hearing impairment that hampers an individual's processing of linguistic information makes this task even more difficult (Myers, 2000). The researchers believe that the respondents' late exposure to formal sign language and late deployment to school affects their English language learning. It can be noticed as well that there are words in English that are difficult to comprehend and to translate using sign language. Lastly, the teacher aided the interview question with sign language and speech and all of the participants responded with sign language.

Table 7: Summary of the Communication Approaches used by the Students

\begin{tabular}{llcc}
\hline Questions for Interview & $\begin{array}{c}\text { Students' } \\
\text { Communication } \\
\text { Approaches }\end{array}$ & Frequency & Percentage \\
\hline 1. Were you born hearing-impaired? & Finger Spelling & 6 & 100 \\
$\quad$ If not, when did you become one? & Sign language & 6 & 100 \\
2. Are your parents also hearing- & Sign language & 6 & 100 \\
$\quad$ impaired? & Sign language & 6 & 100 \\
3. What is your first language? & Sign language & 6 & 100 \\
4. How did you communicate with & & 6
\end{tabular}




\begin{tabular}{llll}
\hline $\begin{array}{l}\text { your parents in your early } \\
\text { childhood? }\end{array}$ & & \\
5. When did you first come into & Sign language & 6 & 100 \\
$\quad \begin{array}{l}\text { contact with English? } \\
\text { 6. How do you master English? }\end{array}$ & Sign language & 6 & 100 \\
7. What challenges can you identify & Sign language & 6 & 100 \\
\hline
\end{tabular}

Table 7 summarizes the communication approaches used by students in each question during the interview. It shows that all respondents used the same communication approaches in responding to each question. Fingerspelling was employed only in question 1 while sign language for all seven questions. This implies that these communication approaches are the most applicable in answering the interview questions and the easiest option in line with their grade level and status as learners of the learning English language. According to Gravel and O'Gara (2003), every communication approach used by hearing-impaired individuals has its own limitation and, thus, no communication approach is optimal. One approach may be useful for one instance but inappropriate for another.

Table 8: Summary of the Communication Approaches used by the Teacher

\begin{tabular}{llc}
\hline \multicolumn{1}{c}{ Questions for Interview } & Teacher's Communication Approaches \\
\hline 1. Were you born hearing-impaired? If not, & Sign Language, Speech \\
when did you become one? & Sign Language, Speech \\
2. Are your parents also hearing-impaired? & Sign Language, Speech \\
3. What is your first language? & Sign Language, Speech \\
4. How did you communicate with your & \\
5. When did you first come into contact with & Sign Language, Speech, Finger Spelling \\
6. How do you master English? & Sign Language, Speech \\
7. What challenges can you identify in & Sign Language, Speech \\
\hline
\end{tabular}

Table 8 reviews the different communication approaches used by the teacher in each question during the interview. It displays that the teacher used sign language, speech and finger spelling in interviewing the students. Every single approach affects the way deaf individuals perceive information. For instance, one idea can be expressed and received using one or two communication approaches but can be ambiguous or cannot be understood at all using other communication approach/es.

The researchers believe that the teacher's choice of communication approaches is directly proportional to the learning level of the students. These are the easiest media to grasp the English lessons. Furthermore, the teacher's communication approaches contribute to every single student's own choice of communication approaches.

Aside from sign language, speech, and finger spelling used by the teacher during the interview, the researchers observed the use of lots of pictures during class discussions. According to Berke (2011) and Bustos (2009), pictures or images or visuals are also considered an approach to communication. Bustos stated that while hearing children are dependent on oral-aural channels, deaf children are dependent on the visual-gestural channel. Their literacy behaviors are grounded on this visual orientation, which helps hearing-impaired students practice their association skills. This leads to a clearer understanding and more refined interaction using English language.

On the other hand, the researchers noticed that participants tend to imitate the actions of their classmates without fully getting the gist of the message. Nevertheless, imitation is significant by virtue of learning new materials and mastery of the language itself (both sign and English).

In the end, the teacher made it clear that the sign language they use in school represents the manually Coded English (MCE) system most of the time. Thus, the sign language indicated in every table is based on manually coded English (MCE) system.

In line with this, three out of seven communication approaches stated in the related literature were found to be the same with the students'. On the other hand, four out of seven were shown to be the same with the teacher's. 


\subsection{Challenges in English Language Learning and Teaching}

\subsubsection{Slow comprehension and Apprehensive Behavior during Class Evaluation:}

The responses indicated that slow comprehension in lesson discussion hinders its progress. Moore (2001), as cited by El-Zraigat and Smadi (2012), claimed that hearing loss negatively affects hearing-impaired students' academic achievement, social and emotional interaction, and cognitive milestones. It was observed too that the teacher had varieties of activities to catch their attention because they easily lost focus in lesson discussion. This signifies because of slow comprehension, focus and motivation in learning are something that is not fully established most of the times. Moreover, students showed anxious facial expressions and often asked the teacher for instructions and guidance during formative and summative tests. The teacher's and the students' responses are quoted below:

T: "Hearing-impaired students are so slow comprehending information... when I ask them a question, they cannot directly give an answer. They lose focus most of the time... Moreover, they become restless during quizzes and examinations..."

S2: "Difficult to understand."

S4: "Difficult to understand. Lots of words to memorize."

\subsubsection{Problematic Retention}

The teacher's sentiments about the students' responses during assessments supported the findings of Hurlbut (2008) and Julsrud (2011) that hearing loss already makes it difficult to achieve academic competence. However, the notion that they are non-native signers (with hearing parents) and have late exposure, considering the age of the participants, not only to structured sign language but also to English language itself, make it even more difficult. It was also noticed that the teacher needed to repeat gestures several times before affirmation was received from the students.

T: "It is difficult for them to remember our lesson. I need to repeat it, every word, and every sentence over and over again for them to implant it in their minds and master it."

S5: "...Lots of words are difficult to memorize."

\section{Conclusion}

After the long period of gathering and analyzing the data, the researchers agree with the study of Gravel and O'Gara (2003) that the hearing-impaired students' mother tongue, the hearing condition of their parents or guardians, the resources available at school, and their grade level affect their knowledge about the different approaches to English language learning. The teacher's communication approaches as well contribute to the learning of the students.

The students' hearing loss also essentially affected their learning level. This explains the many difficulties they encounter such as slow comprehension, apprehensive behavior during class evaluations, and problematic retention. These difficulties manifest the challenges of the teacher herself in teaching the English language. Furthermore, the late language development and slow learning of the participants are evident in the study. However, the researchers believe that these can be attributed to the less interaction opportunities using the target language at home and the scarcity of resources in school. It was noticed that students were merged in a multi-grade classroom, which may mean that the unique needs of each student in terms of learning could not be properly addressed all the time.

The researchers recommend and argue that more than any other educational sector, Special Education Program should be given more emphasis. This is because children with hearing impairment and with other disabilities are not only concentrated in one part of the country but in every area of the Philippines. Moreover, SPED English teachers may enhance the use of communicative strategies in teaching sign language and English in the classroom to develop interaction and production of the hearing-impaired students' language learning. They may also improve classroom evaluation to monitor and provide appropriate measures of the hearing-impaired students' performance to maximize the teaching and learning process; and attend training and seminars regarding English language teaching to hearing-impaired students to allow innovations and to widen their perspective in special education. 
Funding: This research received no external funding.

Conflicts of Interest: The authors declare no conflict of interest.

\section{References}

[1] Akach, P.A.O. (2010). Application of South African sign languages (SASL) in a bilingual-bicultural approach in education of the deaf. [Doctoral Thesis]. University of the Free State, South Africa.

[2] Asif, M. (2008). Difficulties faced by deaf students and their interaction partners during interaction in inclusive secondary classrooms. Fontys University of Applied Science, Tilburg, The Netherlands.

[3] Baker S. \& K. Baker. (1997). Educating children who are deaf and hard of hearing: bilingual-bicultural education. ERIC Clearinghouse on Disabilities and Gifted Education. www.eric.ed.gov

[4] Berke, J. (2011). Using sign language and voice for total communication. Literacy Link: About.com Health's Disease and Condition. Retrieved from: http://deafness.about.com/cs/communication/a/totalcomm.htm

[5] Berent, G. P. (2001). English for deaf students: assessing and addressing learners' grammar development. In D. Janáková (Ed.), International Seminar on Teaching English to Deaf and Hard-of-Hearing Students at Secondary and Tertiary Levels of Education: Proceedings, pp. 124134. Prague, Czech Republic: Charles University, The Karolinum Press.

[6] Bochber, J.H. \& G.G. Walter. (2005). Evaluating deaf students' readiness to meet the English language and literacy demands of postsecondary educational programs. Evaluating Deaf Students' Readiness, pp.232-243.

[7] Bucur, l., (2013). The role of total communication in optimizing the teaching- learning process for the hearing-impaired students. [Doctoral Thesis]. Babes-Bolyai University of Cluj-Napoca.

[8] Bustos, M.T. (2009). Exploring emergent literacy behaviors of Filipino deaf children. The Asia Pacific Education Researcher 16(1), 101-110.

[9] Cornett OR. (1967). Cued Speech. Am Ann Deaf 112: 3-13.

[10] El-Zraigat, I. \& Y. Smadi. (2012). Challenges of educating students who are deaf and hard-of-hearing in Jordan. International Journal of Humanities and Social Sciences 2(6), 150-158.

[11] El-Zraigat, I. (2007). Assessing performance level of students who are deaf and hard-of-hearing in expressive writing skills in Jordan and its relation to some variables. International Jordanian Journal in Education, 3(4), 435-448.

[12] Fraenkel, R. J. and Wallen, E. N. (2006). How to design and evaluate research in education (6 $6^{\text {th }}$ ed.). McGraw-Hill Education.

[13] Goldberg D. (1997). Educating children who are deaf and hard of hearing: Auditory-Verbal. ERIC Clearinghouse on Disabilities and Gifted Education. www.eric.ed.gov

[14] Goldin-Meadow, S. \& R. Mayberry. (2001). How do profoundly deaf children learn to read?. Learning Disabilities Research \& Practice 16(4), 222-229.

[15] Gravel, J. \& J. O'Gara. (2003). Communication options for children with hearing loss. Mental Retardation and Development Disabilities Research Reviews, 9, pp. 243-251

[16] Gregory. S. (1989). Issues in Deaf Education. David Fulton Publishers.

[17] Gustason G. (1997). Educating children who are deaf and hard of hearing: English based sign systems. ERIC Clearinghouse on Disabilities and Gifted Education. www.eric.ed.gov

[18] Horňakova, A. \& A. Hudakova. (2013). Effective communication with deaf patients. JAHR, 4(7), 157- 166

[19] Hurlbut, H.M. (2008). Philippine signed languages survey: a rapid appraisal. SIL Electronic Survey Report.

[20] Johnson, R., S. Lidell \& C. Erting. (1989). Unlocking the curriculum: priniciples for achieving access in deaf education. Graduate Studies and Research. Department of Linguistics and Galludet Research Institute. Galludet Uniersity, Washington, D.C.

[21] Julsrud, M. (2011). First language acquisition in deaf children. [Master's thesis]. University of Adger, Norway.

[22] Kretchmer, R.R. Jr. (1997). Issues in the development and interpersonal discourse for children who have hearing loss. University of Cincinnati, $\mathrm{OH}$.

[23] Martin, V. (2009). Language learning and deafness. [Bachelor thesis]. Masaryk University Brno, Czech Republic

[24] Mayberry, R.I. (2001). Reading development in relation to sign language comprehension. Manuscript.

[25] Mayberry, R.I. (2002). Cognitive development in deaf children: the interface of language and perception in neuropsychology. Handbook of Neuropsychology, 2(8), p. 78.

[26] Moravkova, V. (2011). Deaf students and their motivation to learn English. [Bachelor thesis]. Masaryk University Brno, Czech Republic.

[27] Myers, D. G. (2000) Quiet world: living with hearing loss. Yale University Press.

[28] National Council on Disability Affairs. (2009-2012). Diliman, Quezon City, Philippines. Retrieved from internet: REGION 13 (CARAGA) _ National Council on Disability Affairs.html

[29] Raga, J. (2014). Sign language and English language use: examination performance implications for deaf students at Kuja Secondary School, Migori County, Kenya. Thesis. Kuja Secondary School, Migori County, Kenya.

[30] Robson, C. (2002). Real World Research, (2nd ed.), Oxford: Blackwell.

[31] Sandler, W. \& D. Lillo-Martin. (2001). Natural sign languages. Aronoff, M., Rees-Miller, J. (eds.). Handbook of Linguistics. pp. $533-562$.

[32] Simons, Gary F. \& Charles D. Fennig (eds.). (2017). Ethnologue: Languages of the World, (20th ed.). Dallas, Texas: SIL International. Online version: http://www.ethnologue.com. 